\title{
Container Design Affects Shoot and Root Growth of Vegetable Plant
}

\author{
Jesús Gallegos \\ CIAIMBITAL Research Centre, University of Almeria, Ctra. de Sacramento \\ s/n, E-04120 Almería, Spain
}

\author{
Juan E. Álvaro \\ Pontificia Universidad Católica de Valparaíso, School of Agronomy, Calle \\ San Francisco s/n, La Palma, Quillota, Chile
}

\section{Miguel Urrestarazu \\ CIAIMBITAL Research Centre, University of Almeria, Ctra. de Sacramento s/n, E-04120 Almería, Spain}

Additional index words. internal vertical wall, root surface, container shape, vegetable crops, root impedance

\begin{abstract}
The response of root growth in containers has been studied in recent decades. The objective was to evaluate the effect of four types of containers on root and shoot growth. The containers were two shapes, round and square, and in some containers, internal vertical walls (IVWs) were placed that increased the internal container surface area with two substrates: perlite and coir fiber. Seedlings of cucumber, pepper, and tomato were transplanted. Two experiments were performed: vegetative growth and drought stress by partial decapitation and a period without fertigation. After decapitation, preexisting and new leaf area, dry biomass or the leaves, and stem were measured. The results revealed that the type of container had no effect, nor were there significant differences between substrates. The containers with IVWs exhibited an increase in biomass and the root surface. The total contact surface with the substrate of the four container types was closely related to the recorded plant growth. Thus, IVWs not only decrease mechanical problems of roots by preventing spiralling but also favor the production of biomass in vegetable plants and substantially increase the root, enabling the plants to manage water deficit and potentially improve posttransplant stress.
\end{abstract}

The response of roots to mechanical impedance has intrigued horticulturists, plant biologists, and substrate physicists for at least two centuries (Araki and Iijima, 2001; Atwell, 1993), whereas the model of root growth as a function of multiple variables in a container remains far from being completely understood. Spencer-Lemaire Industries attempted to design a container that would include the benefits of other systems, and grooves were included in the design because it was believed that they would reduce root spiralling; this was then borne out in practice (Spencer, 1972). The design of containers has increased the advantages of this technique: to produce better-quality seedlings in individual containers, minimize root deformations, mechanize production, facilitate planting, and allow control of mineral nutrition parameters. However, improvements remain to be developed.

Received for publication 21 Feb. 2020. Accepted for publication 4 Mar. 2020.

Published online 27 April 2020.

We gratefully acknowledge the support of the Mexican National Council for Science and Technology (CONACYT) for its financial support of this work.

M.U. is the corresponding author. E-mail: mgavilan@ ual.es.

This is an open access article distributed under the CC BY-NC-ND license (https://creativecommons. org/licenses/by-nc-nd/4.0/).
The substrate, fertilization, and fertigation of a culture container, there are multiple aspects that can affect root growth and, subsequently, a plant's aerial growth.

Multiple studies indicate that the size, volume, shape, depth, color, and even roughness of a container's internal walls affect the growth characteristics of plants, particularly the quality of their root system (Lemaire et al., 2005; Lemaire and Papin, 1989; Liptay and Edwards, 1994; Rune, 2003; South et al., 2005; Spencer, 1972; Yano et al., 2018).

The morphology of a container is one of the primary factors to consider because its design determines the morphological and physiological characteristics of seedlings, primarily in terms of their root systems (Aphalo and Rikala, 2003; Dominguez-Lerena et al., 2006; Landis, 1990; Sánchez-Aguilar et al., 2016; Spencer, 1972).

With identical substrate filling, containers with a predominant horizontal axis have the advantage of greater water retention because the water pressure column is smaller (Ansorena, 1994). Various studies, such as those of Heller et al. (2015) on the geometry of a container (from narrow and tall containers to wide and short containers) holding lettuce, found that shape does not affect yield when the containers are of identical volume. However, when a plant is in a container for a long period, the depth of the container determines the length of the plant's main root and therefore the plant's survival under limiting conditions, as determined from stimulating aerial and root growth after the transplant of various woody plants (Biran and Eliassaf 1980; Chirino et al., 2008; Pemán et al., 2006; Landis et al., 2014; Trinidad et al., 2015).

Through industrial patents, the design of containers has permitted many container shapes (round, rectangular, hexagonal, or square and tapered from top to bottom) to be tested with forest plants (Ferrand, 1971; Guggenheim and Odle, 2016), with ornamentals (Kreizel, 2002; Lüken and Sieverding, 2009) and in horticulture. In early experimental tests, Spencer (1972) implemented vertically oriented crests, ribs, or grooves that represented a mechanical impediment or obstacle to spiralling root growth. However, the perfect container has yet to be developed because it depends on the purposes of use and the species cultivated (Landis, 1990). Many of the modifications to the design of container properties are performed to avoid root deformations (Neddo et al., 1977) and to direct the roots of seedlings downward (Cooley, 2011), resulting in the development of the important growth of straight roots extending through the vertical axis of the container, with the addition of vertical grooves along the cell up to the opening of the drainage holes (Spencer, 1972), as described in Spencer (1991) and Spencer (1977). Some container design modifications have been developed to facilitate handling, rigidity (Bokmiller et al., 2000; Quan et al., 2011; Schromm, 2009;), durability, stacking (Sieverding, 2007), transport (Nilsson and Fransson, 2017; Park, 1966; Schmidt, 2009), removal without damage to plants (Spencer, 1991), labeling (Skinner, 2002), and avoiding adhesion between containers (Stockdale, 1961). Other design functions allow for the aerial pruning of roots in drainage holes and provide an adequate balance of moisture in the culture medium (Insalaco, 1975; Staby, 1979), or they combine ease of aerial pruning with the classic function by Spencer (1972), satisfying mechanical deflection by including ribs on the internal container surfaces (Rune, 2003).

Gilman et al. (2003) and Amoroso et al. (2010) reported that plants grown in plastic containers with smooth walls during one crop cycle generate deformed roots with spiral movements, an impediment to horizontal growth. Root deformations and their influence on posttransplant growth parameters have been studied (Lemaire and Papin, 1989; Spencer, 1972) due to their importance in ornamental, vegetable, and forest crops. Root spiralling is one of the most important factors influencing vegetative and root development, in addition to field survival (Brass et al., 1996), and is a possible influence on flowering (Armitage and Gross, 1996).

Container selection should therefore be in accordance with the characteristics that are specific to 1) the root system (Keever and Cobb, 1987), 2) the duration of the intended container culture (Lemaire et al., 2005), and 3 ) the combination of the culture medium 
Table 1. Types of containers used and their characteristics (see Fig. 1).

\begin{tabular}{|c|c|c|c|c|c|c|c|}
\hline & $\begin{array}{l}\text { Types of } \\
\text { container }\end{array}$ & $\begin{array}{c}\text { Cross } \\
\text { section }\end{array}$ & $\begin{array}{l}\text { Container total } \\
\text { volume }(\mathrm{mL})\end{array}$ & $\begin{array}{c}\text { Substrate } \\
\text { volume }(\mathrm{mL})\end{array}$ & $\begin{array}{l}\text { No. of internal } \\
\text { vertical walls }\end{array}$ & $\begin{array}{l}\text { Individual area of each vertical } \\
\text { wall with the substrate }\left(\mathrm{cm}^{2}\right)\end{array}$ & $\begin{array}{l}\text { Contact area between } \\
\text { root and container }\left(\mathrm{cm}^{2}\right)\end{array}$ \\
\hline$\overline{\mathrm{O}}$ & Truncated cone & Circular & 462 & 350 & - & - & 216 \\
\hline$\square$ & Truncated pyramid & Square & 521 & 350 & - & - & 247 \\
\hline$\oplus$ & Truncated cone & Circular & 462 & 350 & 4 & 24.55 & 314 \\
\hline$\boxplus$ & Truncated pyramid & Square & 521 & 350 & 4 & 28.64 & 362 \\
\hline
\end{tabular}

(Bilderback and Fonteno, 1987) with its fertigation (Urrestarazu et al., 2017).

Although there are studies on the effects of root growth, development, and production of vegetable plants as a function of mineral nutrition (Dixon, 2019; Urrestarazu, 2015; Urrestarazu et al., 2008), irrigation (Salter, 1961), the internal roughness and smoothness in seedling trays on tomato plants (Liptay and Edwards, 1994), and in forest nurseries (Amoroso et al., 2010; Spencer, 1972). Roots often grow along the surface of the pots, and thus a large surface area may increase root growth; however, there is scant information on container morphology designs that result in an increase in root area for containers with the same volume that have inner vertical walls. Some benefit may be derived from incorporating an increase in the contact surface between the container and the root that grows within the spatial limits of the container walls. The aim of this study was to evaluate the effect of the morphology of four types of square and round containers, with and without internal vertical walls, on plant growth, root surface, and the response to a period of drought stress in cucumber, pepper, and tomato crops.

\section{Materials and Methods}

The experiment was conducted at the University of Almeria (Spain) in a multitunnel plastic greenhouse located at coordinates lat. $36^{\circ} 49^{\prime} 45^{\prime \prime} \mathrm{N}$, long. $2^{\circ} 24^{\prime} 16^{\prime \prime} \mathrm{W}$. The average night and day temperatures of the greenhouse were 15 to $20{ }^{\circ} \mathrm{C}$ and 20 to $35{ }^{\circ} \mathrm{C}$, respectively. Before cultivation, the greenhouse and containers were disinfected with $3 \%$ peracetic acid, as recommended by Álvaro et al. (2009).

Plant material. Two independent experiments were performed: one on vegetative growth and analysis of the root surface per substrate volume and one on drought stress by partial decapitation and a period of fertigation suppression. The plant material was cucumber (Cucumis sativus L.) cv. SV0091CE, pepper (Capsicum annuum L.) cv. Valenciano and tomato (Solanum lycopersicum L.) cv. Granoval. The plants were seeded in coir fiber (composed of $85 \%$ fiber and $15 \%$ dust), and perlite Agroperl B12, and transplanting was performed to the final container treatments at the two-true-leaf stage in cucumber and the four-true-leaf stage for pepper and tomato. The physicochemical properties of the Pelemix coir fiber used were described by Rodríguez et al. (2014), and the properties of perlite Agroperl B12 were described by Urrestarazu (2015) and Urrestarazu et al. (2017).
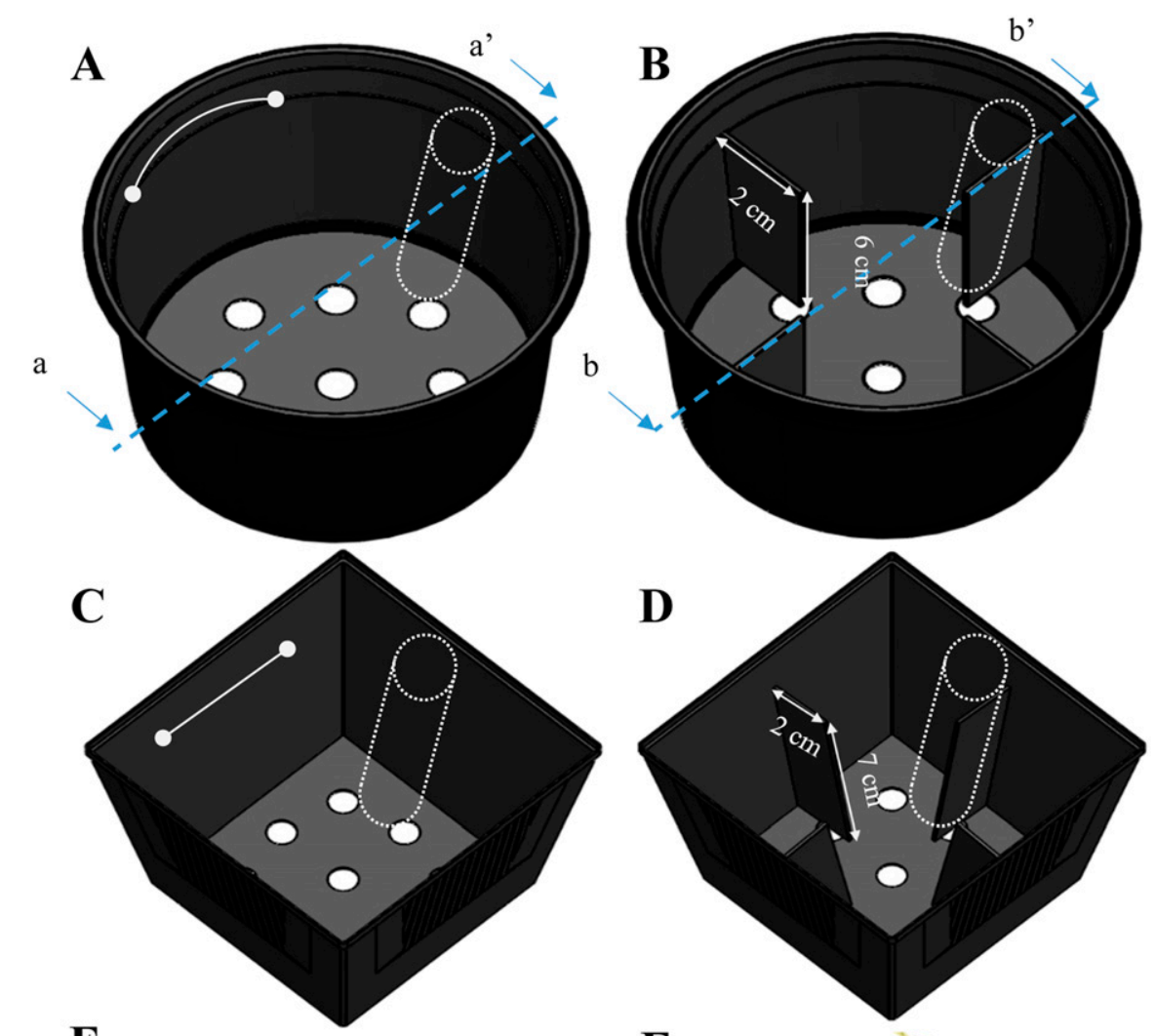

$\mathbf{E}$

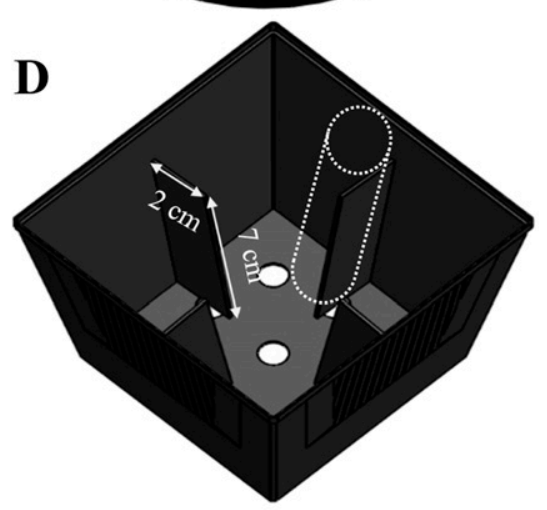

$\mathbf{F}$

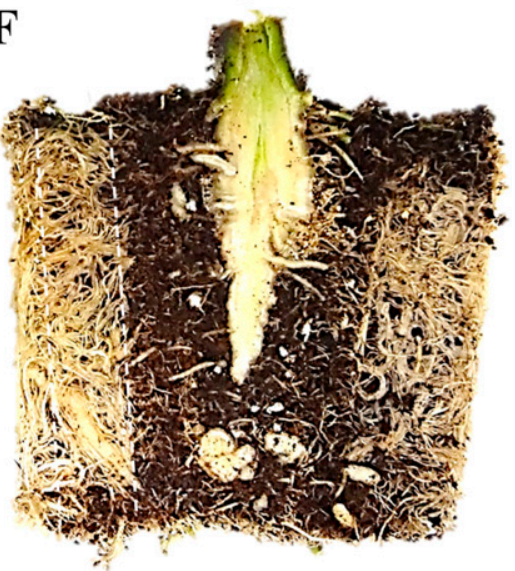

Fig. 1. (A and B) Round pot without $(\bigcirc)$ and with $(\oplus)$ internal vertical walls, respectively. (C and D) The same pot but squared. ( $\mathbf{E}$ and $\mathbf{F}$ ) The vertical section from tomato crops in coir fiber in container $\mathrm{A}$ and B. a-a' and b-b' are vertical section of tomato roots by coir in pot A and B. The dotted lines represent the area or view of the cross section where root sampling is done. Continuous line indicates the filling level of the substrate in the pot $(350 \mathrm{~mL})$.

Treatments. The treatments consisted of four types of 0.5 -L containers. Two shapes of commercial containers, round and square, manufactured by Pöppelmann TEKU (Germany) were used, with the series VCG and VQB denominations, respectively, within which walls were added as conventionally assembled plastic sheets that increased the interior container surface area (Fig. 1, Ta- ble 1). The treatments were as follows: $\bigcirc$, round containers without internal vertical walls; $\oplus$, round section containers with internal vertical walls; $\square$, square containers without internal vertical walls; and $\boxplus$, square containers with internal vertical walls. The dimensions of the internal walls of containers $\oplus$ and $\boxplus$ were $2 \times 6$ and $2 \times 7 \mathrm{~cm}$, respectively. 
The total contact surface for each container morphology (At, expressed in $\mathrm{cm}^{2}$ ) with $350 \mathrm{~mL}$ of substrate and each type of container was calculated. Table 1 summarizes the calculation specifications of the total contact surface (At) between the height of the substrate in relation to the container morphology, expressed in square centimeters for each type of container.

Fertigation system. A standard nutrient solution was used for EC $2.2(\mathrm{dS} / \mathrm{m})$ according to the ionic nutrient balance based on Sonneveld and Straver (1994). The $\mathrm{pH}$ was adjusted to 5.8 with the addition of diluted nitric acid. Fertigation was performed manually once $10 \%$ of the easily available water in the substrate was exhausted and the volume necessary to obtain $20 \%$ to $30 \%$ drainage was reached, and fertigation programming was adjusted for monitoring the drainage $\%, \mathrm{pH}$ and EC parameters according to the crop (Rodríguez et al., 2015; Urrestarazu et al., 2019).

Crop growth parameters. At $30 \mathrm{~d}$ posttransplant, vegetative growth parameters were measured at the 10-true-leaf stage in cucumber, the 15-true-leaf stage in pepper, and the 11-true-leaf stage in tomato. The leaf area parameters were measured $\left(\mathrm{cm}^{2} /\right.$ plant, measured with image capture using an Alpha 58 digital reflex camera, Japan), similar to that described by Bignami and Rossini (1996), and processed in AutoCAD (2016) (Fig. 2).

Plants were separated into leaves, stems, and roots, and the dry weight (grams/plant) was obtained using an OHAUS Adventurer Analytical Precision Analytical Balance (model AX124/E), with a precision of 0.001 g. The dry weight (g/plant) of each plant part was obtained by placing the material in a forced air oven (Thermo Scientific Heratherm, Germany) at $75{ }^{\circ} \mathrm{C}$ until constant weight was achieved.

Root surface by volume of substrate. In all treatments, a root sample was extracted perpendicular to the container and another parallel to the internal vertical walls (in the containers that had them) using a $9.2-\mathrm{cm}$ high cylindrical punch with a radius of $0.5 \mathrm{~cm}$ (Fig. 1). Root samples were placed on 140$\mathrm{mm}$ petri dishes (Thermo Scientific Sterilin) with graph paper, and the individual root count was performed manually at two depths: 0 to 4 and 4 to $8 \mathrm{~cm}$. The root was determined, as was the number of roots with root thickness $\geq 0.25 \mathrm{~mm}$ and $\leq 1.25 \mathrm{~mm}$, similar to that reported by Urrestarazu et al. (2015). The root surface (RS, expressed in $\mathrm{cm}^{2} / \mathrm{cm}^{3}$ ) was calculated according to the following equation for each of the samples measured at different depths in both substrates and for each crop:

$$
\mathrm{RS}=(\mathrm{RL} 2 \pi \mathrm{r} 0.01) / \mathrm{V}_{\mathrm{p}},
$$

where RL is the root length of each sample $(\mathrm{mm}), \mathrm{r}$ is the root thickness ( $\mathrm{mm})$, and $\mathrm{Vp}$ corresponds to the cylindrical punch volume $\left(\mathrm{cm}^{3}\right)$.

Drought stress test. In the second experiment, plants were decapitated at the stem at $30 \mathrm{~d}$ after transplant. After watering to saturation, a cut was made above the second true
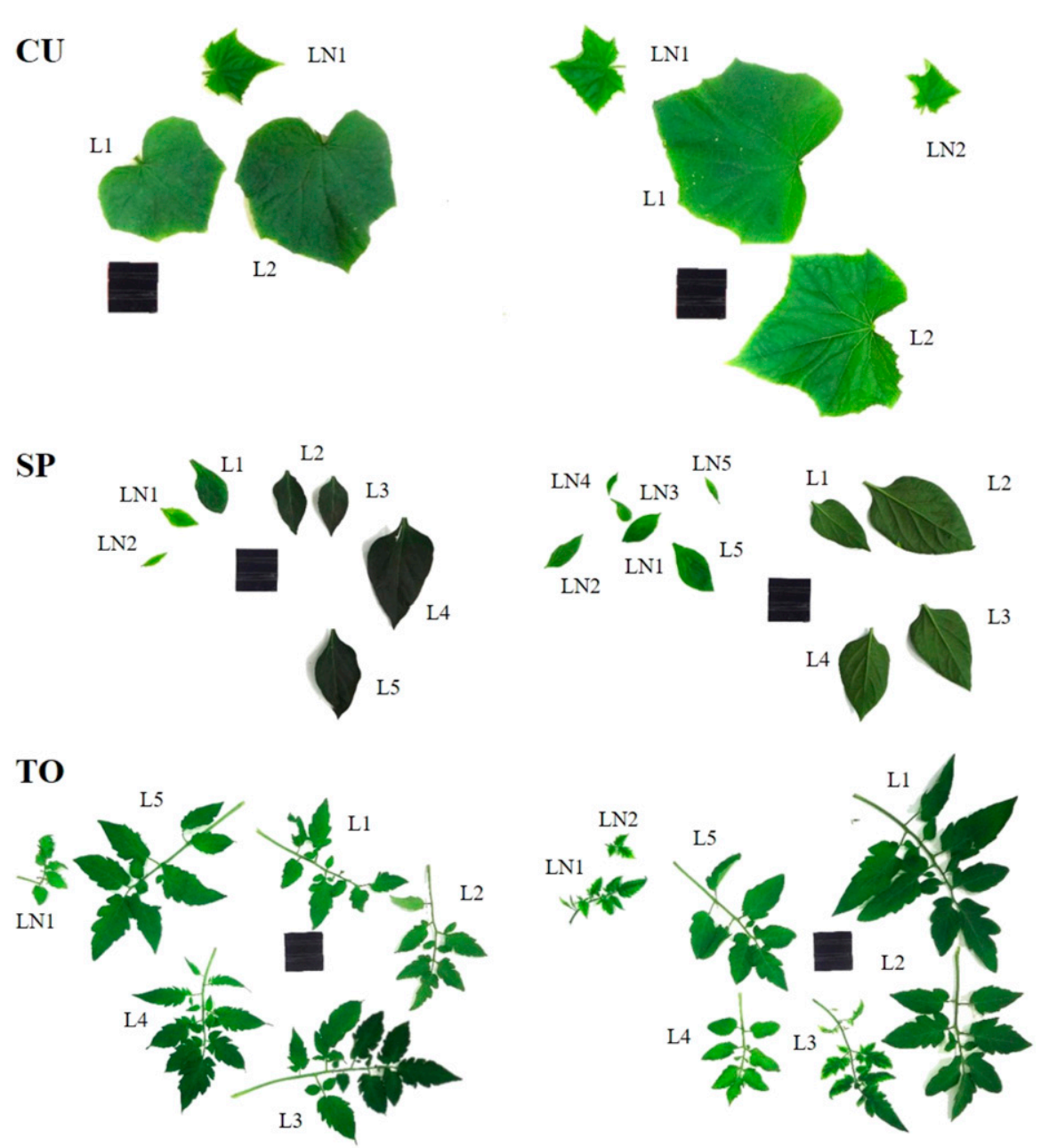

Fig. 2. Leaf area of cucumber (CU), pepper (SP, and tomato (TO) without (left) and with internal vertical walls (right) measured after 8 d under water stress. L1, L2, L3, L4, and L5, are the first, second, third, fourth, and fifth true leaf respectively. LN1, LN2, LN3, LN4, and LN5 are the new leaves. Square black is the reference of $25 \mathrm{~cm}^{2}$.

leaf in cucumber and the fifth true leaf in pepper and tomato (Fig. 3). The plants were maintained for $8 \mathrm{~d}$ under greenhouse conditions without fertigation until substrate exhaustion of $100 \%$ of the easily available water, before the permanent wilting point. After this period of drought stress, the plants were divided into preexisting leaves, new leaves, stems, roots, and axillary buds for measurement. Additionally, the leaf area of preexisting leaves and new leaves $>1 \mathrm{~cm}^{2}$ were measured (Fig. 2).

Statistical analysis and experimental design. For each crop and substrate, a random experimental design of four randomized complete blocks was performed (Montgomery, 2004). Each block was composed of five plants per treatment and four replicates. The results were subjected to an analysis of variance, and a separation of means was performed using a least significant difference test at $P \leq 0.05$. The mathematical treatment of the data were performed using the Statgraphics Centurion XVIII (2018) and Excel from Microsoft Office (2016) software packages.

A simple linear regression was performed, with the correlation coefficient $\left(R^{2}\right)$ between the total contact surface of the container (Table 1) in relation to the leaf area $\left(\mathrm{cm}^{2} /\right.$ plant) and the dry weight (g/plant) of the new shoots (Fig. 4) (Gallegos-Cedillo et al., 2016).

\section{Results and Discussion}

Growth parameters of different horticultural crops with respect to container type and substrate

Effect of external container shape. Container morphology did not exert any clear effect on the plant growth parameters measured for any crop or on either substrate (Table 2). In a study on tomato plants, Liptay and Edwards (1994) found that the morphology of container walls in tomato seedlings affected root growth, whereas Heller et al. (2015) found no significant differences in lettuce plants when working with different container morphologies with the same fertigation method.

Effect of walls inside a container. The presence of vertical walls inside the containers exerted a clear and significant effect on most of the growth parameters measured. The cucumber leaf area increased by $\approx 10 \%$ 
A
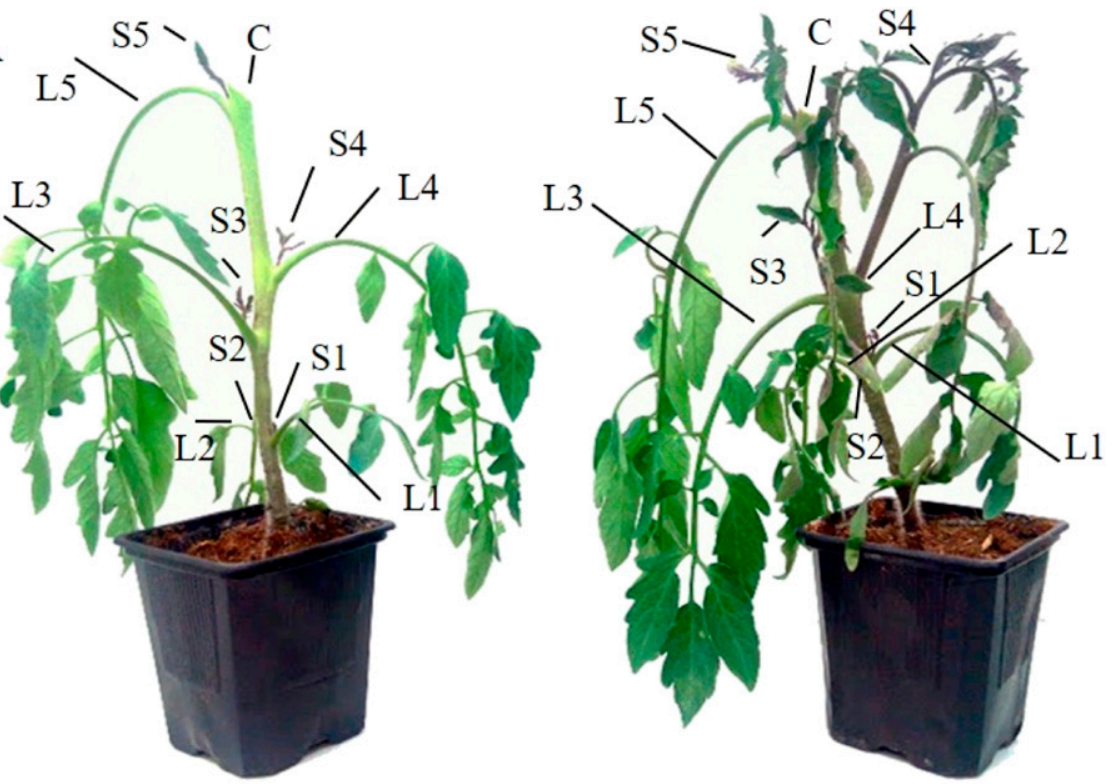

B

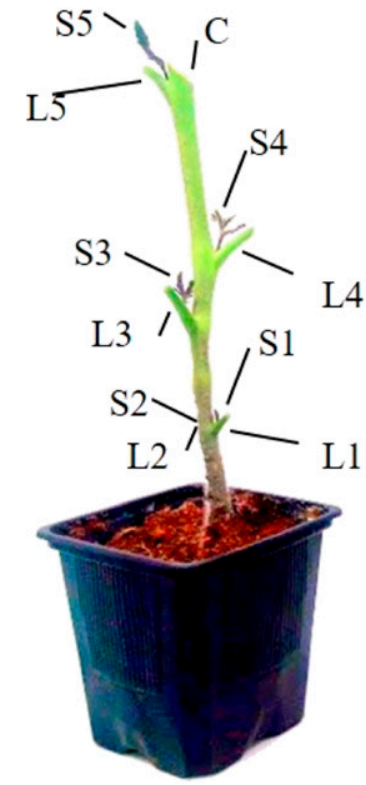

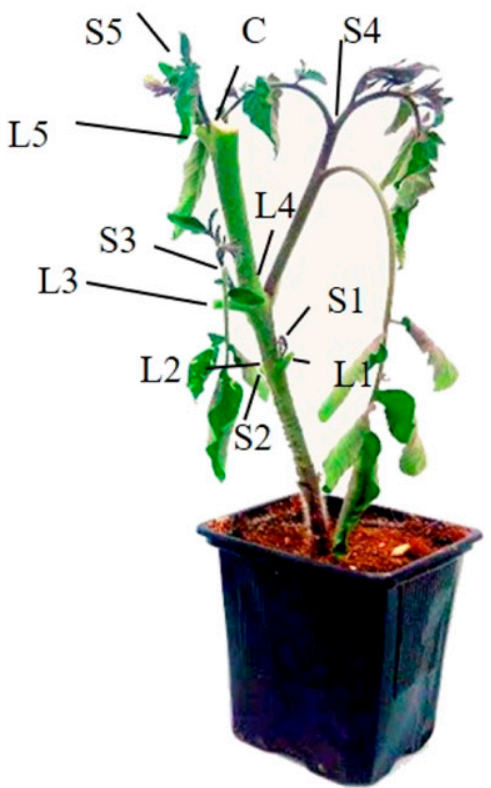

Fig. 3. (A) Tomato plants without (left) and with (right) vertical internal walls in the container after decapitation in the stem (point $\mathrm{C}$ ) and a water stress period of $8 \mathrm{~d}$. (B) The same plants of A after the cutting of the preexisting true leaves. L1, L2, L3, L4, and L5, are the first, second, third, fourth, and fifth true leaf respectively. S1, S2, S3, S4, and S5 are the axillary leaf buds of the first, second, third, fourth, and fifth true leaves, respectively.

for both substrates in containers with internal walls. For pepper and tomato, a significant increase was recorded only when using perlite (Table 2). For the root growth parameters, this increase was similar in both substrates-20\% for all crops-whereas the total biomass increased by only $10 \%$. Liptay and Edwards (1994) found significant differences in root growth, whereas there was no clear effect on shoot growth. Rune (2003) found different results in Scots pine depending on the applied fertilization; using containers with vertical ribs promoted better root growth. Amoroso et al. (2010) found no significant differences in shoot biomass in littleleaf linden (Tilia cordata Mill.) and field elm (Ulmus minor Mill.) seedlings; however, when comparing smooth walls (in a round container) to containers with vertical ribs (in square containers), scant differences in root biomass appeared in favor of smooth walls, whereas deformed roots were significantly less common in containers with vertical ribs. The benefits of internal walls appear clear for 1) improving plants' roots (e.g., Amoroso et al., 2010; Liptay and Edwards, 1994), 2) the potential rupture of the preferential channels that are formed in the fertigation flow pattern inside a container (Urrestarazu et al., 2017), and 3) the flow pattern in a saturated or halfsaturated substrate in response to fertigation movement within the substrate (De Rijck and Schrevens, 1998).
Root surface according to container shape and substrate

Effect of external container shape. The average distribution data of the root surface per unit volume of substrate coincided with established knowledge of vegetable plants (cucumber) in soilless culture in rockwool (Van Noordwijk and Raats, 1980) (Table 3). Apart from some exceptions in the cultivation of pepper and tomato in favor of square containers, container morphology exerted little influence on the root surface both in the entire volume of substrate and in the surface $(0-4 \mathrm{~cm})$ and bottom $(4-8 \mathrm{~cm})$ layers. In both morphologies, deeper sampling of a container exhibited greater root growth at greater depths, a trend similar to that reported in tomato plants grown in traditional soils (Reid et al., 1996) and soilless cultivation (Urrestarazu et al., 2015). Moreover, temperature variation at soil depths can modify the root growth pattern (Kaspar and Bland, 1992).

Effect of walls inside a container. For identical container shape, there was always an increase of root surface area regardless of both substrates and of depths and types of species $(>34 \%)$ for containers with internal walls. The greater distribution of roots around the walls confirms the results described in Table 2, in which there was a higher root biomass in containers that had interior vertical walls. However, identifying root system architecture is of vital importance to ensuring productive success (Mansoorkhani et al., 2014) because it enables more efficient and effective fertigation, given the existence of humidification bulb distribution patterns in different fertigation conditions and substrate types (Urrestarazu, 2015; Urrestarazu et al., 2017).

\section{Growth parameters after a period of drought stress}

Effect of container morphology. Table 4 presents the results of the biomass data from the drought stress experiment. The same trends that were shown in Table 2 for the vegetative growth values of entire plants are presented. The root growth parameters were similar in both substrates; this trend may be a consequence of using the same volume of substrate and the previous fertigation adjustment to the characteristics of the substrate reported previously, for example, in García et al. (1997), Mascarini et al. (2012) for mineral substrates or Verlodt and Kamoun (1981) in organic substrates.

Effect of walls inside a container. Before the decapitation of the three cultivars and substrates, the trend was similar to that described in Table 2 for entire plants. The roots that grew in containers with walls had greater biomass: cucumber and pepper increased by $50 \%$ on average compared with the control, and tomato increased by $15 \%$ in both substrates.

The leaf area of new leaves and the dry weights of shoots after decapitation and drought stress doubled in value in containers with inner walls. This significant increase was very similar in the three cultivars and in 

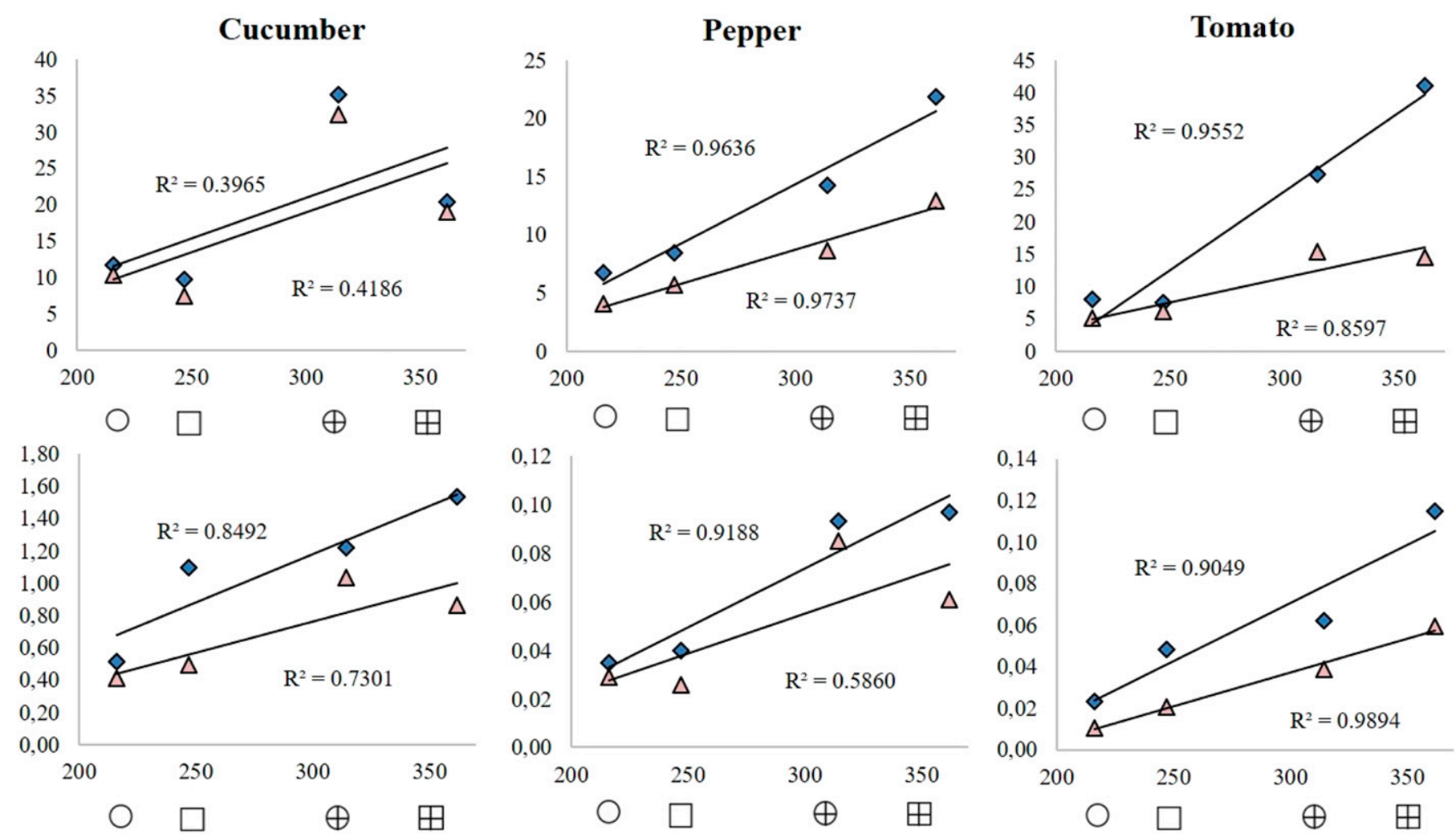

Fig. 4. Linear correlation between the contact surface in the container $\left(\mathrm{cm}^{2}\right)$ and the leaf surface $\left(\mathrm{cm}^{2} /\right.$ plant, upper row) and the dry weight (g/plant, lower row) of the new shoots after decapitation and suppression of the fertigation. The diamonds and triangles indicate the containers with coir fiber and perlite, respectively. $O=$ circular section containers without internal vertical walls; $\oplus=$ circular section containers with internal vertical walls; $\square=$ square section containers without internal vertical walls; and $\boxplus=$ square section containers with internal vertical walls.

Table 2. Leaf area ( $\mathrm{cm}^{2} /$ plant) and biomass (g/plant) of several horticultural crops vs. container and substrate.

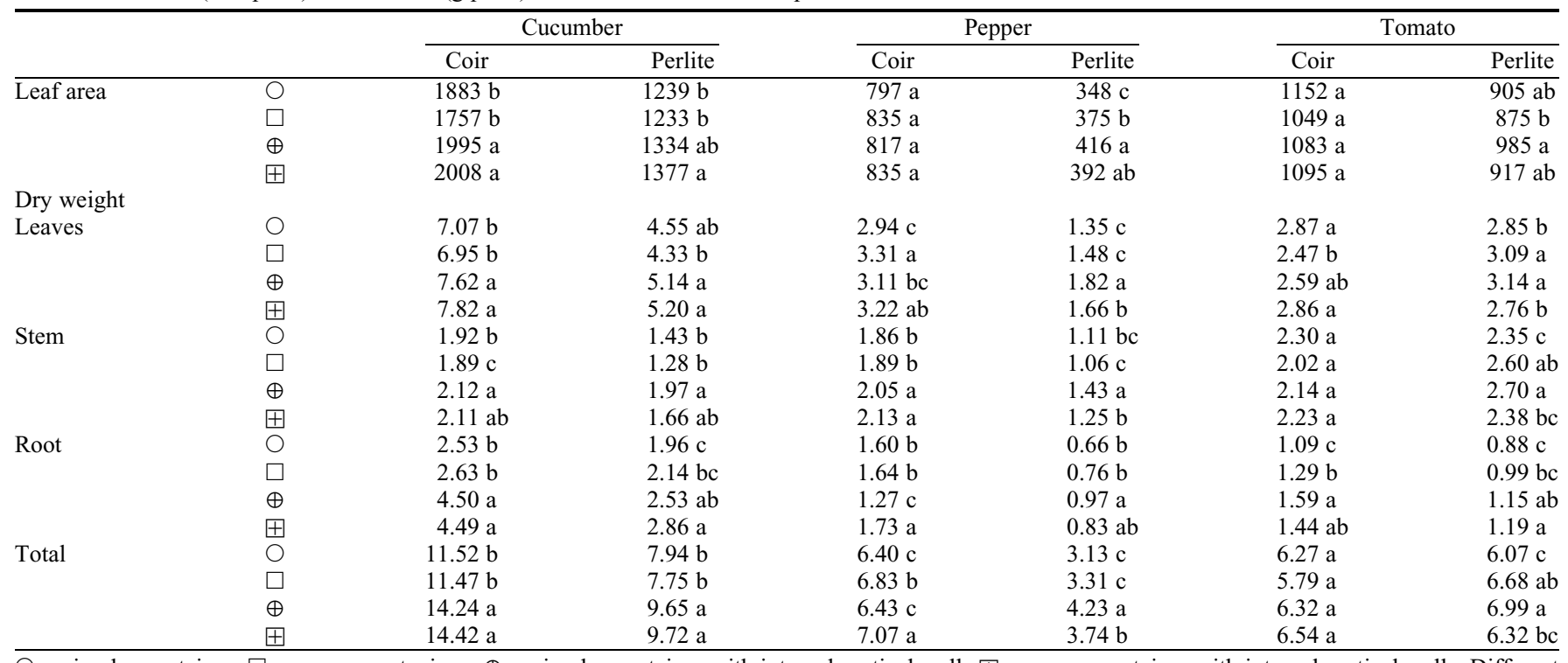

$\mathrm{O}=$ circular container; $\square=$ square contaniner; $\oplus=$ circular container with internal vertical wall; $\oplus=$ square container with internal vertical walls. Different letters in a column indicate significant difference at $P \leq 0.05$ according to the least significant difference test.

the two substrates. Amoroso et al. (2010) found that the shoot biomass was unaffected by the type of container at the end of the first stage of growth, nor was the root biomass at the end of the second year; however, they suggest that the container typology with vertical ribs has a strong influence on the conformation and quality of a plant's root system.
With the exception of the leaf area of the new leaves in cucumber, clear correlations were recorded between the total contact surface of the container and the foliar area of the new leaves and the dry weight of the shoots after the decapitation and drought stress treatments (Fig. 4). Although a clear correlation of these parameters in cucumber with the contact surface, between the container and roots, was not observed, the leaf area was greater in the two treatments with internal walls compared with containers without internal walls.

In summary, a significant mean increase in biomass $(\approx 20 \%)$ (Table 2 ) and root surface $(\approx 30 \%$ to $35 \%$ ) (Table 3 ) doubled or tripled the growth parameters of a shoot when subjected to drought stress (Table 4, Fig. 3), 
Table 3. Root area $\left(\mathrm{cm}^{2} / \mathrm{cm}^{3}\right)$ at different deeps of container measured on position of internal vertical walls vs. type of container and substrate.

\begin{tabular}{|c|c|c|c|c|c|c|c|}
\hline & & \multicolumn{2}{|c|}{ Cucumber } & \multicolumn{2}{|c|}{ Pepper } & \multicolumn{2}{|c|}{ Tomato } \\
\hline \multicolumn{2}{|c|}{ Centimeters from upper surface } & Coir & Perlite & Coir & Perlite & Coir & Perlite \\
\hline \multirow[t]{4}{*}{$\overline{0-4}$} & $\bigcirc$ & $5.14 \mathrm{~b}$ & $4.21 \mathrm{~b}$ & $1.51 \mathrm{c}$ & $0.57 \mathrm{~b}$ & $0.87 \mathrm{c}$ & $1.71 \mathrm{a}$ \\
\hline & $\square$ & $4.02 \mathrm{~b}$ & $4.73 \mathrm{~b}$ & $2.13 \mathrm{~b}$ & $0.51 \mathrm{~b}$ & $0.82 \mathrm{c}$ & $1.30 \mathrm{~b}$ \\
\hline & $\oplus$ & $6.52 \mathrm{a}$ & $7.21 \mathrm{a}$ & $2.09 \mathrm{~b}$ & $0.82 \mathrm{a}$ & $1.24 \mathrm{~b}$ & $1.90 \mathrm{a}$ \\
\hline & $\boxplus$ & $7.41 \mathrm{a}$ & $6.77 \mathrm{a}$ & $2.65 \mathrm{a}$ & $0.95 \mathrm{a}$ & $1.83 \mathrm{a}$ & $1.60 \mathrm{ab}$ \\
\hline \multirow[t]{4}{*}{$4-8$} & $\bigcirc$ & $7.32 \mathrm{~b}$ & $5.73 \mathrm{~b}$ & $1.96 \mathrm{c}$ & $0.64 \mathrm{~d}$ & $0.93 \mathrm{~b}$ & $2.00 \mathrm{~b}$ \\
\hline & $\square$ & $6.57 \mathrm{~b}$ & $5.93 \mathrm{~b}$ & $2.19 \mathrm{bc}$ & $0.85 \mathrm{c}$ & $1.05 \mathrm{~b}$ & $1.90 \mathrm{~b}$ \\
\hline & $\oplus$ & $9.91 \mathrm{a}$ & $9.64 \mathrm{a}$ & $2.33 \mathrm{~b}$ & $1.10 \mathrm{~b}$ & $1.74 \mathrm{a}$ & $2.75 \mathrm{a}$ \\
\hline & $\boxplus$ & $9.65 \mathrm{a}$ & $8.69 \mathrm{a}$ & $2.72 \mathrm{a}$ & $1.32 \mathrm{a}$ & $1.80 \mathrm{a}$ & $2.95 \mathrm{a}$ \\
\hline \multirow[t]{4}{*}{ Total } & $\bigcirc$ & $12.46 \mathrm{~b}$ & $9.94 \mathrm{~b}$ & $3.47 \mathrm{c}$ & $1.21 \mathrm{c}$ & $1.79 \mathrm{c}$ & $3.71 \mathrm{~b}$ \\
\hline & $\square$ & $10.59 \mathrm{~b}$ & $10.66 \mathrm{~b}$ & $4.32 \mathrm{~b}$ & $1.36 \mathrm{c}$ & $1.87 \mathrm{c}$ & $3.20 \mathrm{~b}$ \\
\hline & $\oplus$ & $16.43 \mathrm{a}$ & $16.85 \mathrm{a}$ & $4.41 \mathrm{~b}$ & $1.92 \mathrm{~b}$ & $2.98 \mathrm{~b}$ & $4.65 \mathrm{a}$ \\
\hline & $\boxplus$ & $17.06 \mathrm{a}$ & $15.46 \mathrm{a}$ & $5.36 \mathrm{a}$ & $2.27 \mathrm{a}$ & $3.63 \mathrm{a}$ & $4.55 \mathrm{a}$ \\
\hline
\end{tabular}

$\bigcirc=$ circular container; $\square=$ square contaniner; $\oplus=$ circular container with internal vertical wall; $\boxplus=$ square container with internal vertical walls. Different letters in a column indicate significant difference at $P \leq 0.05$ according to least significant difference test.

Table 4. Leaf area ( $\mathrm{cm}^{2} /$ plant) and biomass (g/plant) of several horticultural crops vs. container and substrate after partial decapitation and water stress.

\begin{tabular}{|c|c|c|c|c|c|c|c|}
\hline & & \multicolumn{2}{|c|}{ Cucumber } & \multicolumn{2}{|c|}{ Pepper } & \multicolumn{2}{|c|}{ Tomato } \\
\hline & & Coir & Perlite & Coir & Perlite & Coir & Perlite \\
\hline \multirow[t]{4}{*}{ Area old leaves } & $\mathrm{O}$ & $180.47 \mathrm{~b}$ & $208.20 \mathrm{a}$ & $205.49 \mathrm{~b}$ & $148.52 \mathrm{c}$ & $399.19 \mathrm{ab}$ & $327.42 \mathrm{a}$ \\
\hline & $\square$ & $166.22 \mathrm{c}$ & $168.39 \mathrm{~b}$ & $228.52 \mathrm{a}$ & $167.67 \mathrm{ab}$ & $386.92 \mathrm{~b}$ & $328.61 \mathrm{a}$ \\
\hline & $\oplus$ & $211.32 \mathrm{a}$ & $212.97 \mathrm{a}$ & $221.29 \mathrm{ab}$ & $161.83 \mathrm{bc}$ & $409.25 \mathrm{ab}$ & $355.01 \mathrm{a}$ \\
\hline & $\boxplus$ & $202.87 \mathrm{a}$ & $204.08 \mathrm{a}$ & $233.60 \mathrm{a}$ & $178.23 \mathrm{a}$ & $423.82 \mathrm{a}$ & $351.86 \mathrm{a}$ \\
\hline \multirow[t]{4}{*}{ Area new leaves } & $\bar{\bigcirc}$ & $11.72 \mathrm{c}$ & $10.32 \mathrm{c}$ & $6.72 \mathrm{~d}$ & $4.01 \mathrm{~d}$ & $7.97 \mathrm{c}$ & $5.06 \mathrm{~b}$ \\
\hline & $\square$ & $9.71 \mathrm{c}$ & $7.50 \mathrm{c}$ & $8.46 \mathrm{c}$ & $5.68 \mathrm{c}$ & $7.40 \mathrm{c}$ & $6.08 \mathrm{~b}$ \\
\hline & $\oplus$ & $35.13 \mathrm{a}$ & $32.34 \mathrm{a}$ & $14.20 \mathrm{~b}$ & $8.65 \mathrm{~b}$ & $27.34 \mathrm{~b}$ & $15.26 \mathrm{a}$ \\
\hline & $\boxplus$ & $20.40 \mathrm{~b}$ & $18.98 \mathrm{~b}$ & $21.80 \mathrm{a}$ & $12.92 \mathrm{a}$ & $41.08 \mathrm{a}$ & $14.42 \mathrm{a}$ \\
\hline \multicolumn{8}{|l|}{ Dry weight } \\
\hline \multirow[t]{4}{*}{ Leaves } & $\bigcirc$ & $1.30 \mathrm{~b}$ & $1.48 \mathrm{a}$ & $0.88 \mathrm{~b}$ & $0.71 \mathrm{c}$ & $1.31 \mathrm{a}$ & $1.14 \mathrm{~b}$ \\
\hline & $\square$ & $1.19 \mathrm{~b}$ & $0.95 \mathrm{c}$ & $0.97 \mathrm{ab}$ & $0.79 \mathrm{~b}$ & $1.35 \mathrm{a}$ & $1.21 \mathrm{ab}$ \\
\hline & $\oplus$ & $1.67 \mathrm{a}$ & $1.66 \mathrm{a}$ & $0.99 \mathrm{ab}$ & $0.84 \mathrm{ab}$ & $1.38 \mathrm{a}$ & $1.29 \mathrm{a}$ \\
\hline & $\boxplus$ & $1.51 \mathrm{a}$ & $1.25 \mathrm{~b}$ & $1.13 \mathrm{a}$ & $0.88 \mathrm{a}$ & $1.38 \mathrm{a}$ & $1.35 \mathrm{a}$ \\
\hline \multirow[t]{4}{*}{ Stem } & 0 & $1.88 \mathrm{a}$ & $0.80 \mathrm{ab}$ & $1.40 \mathrm{a}$ & $1.35 \mathrm{~b}$ & $1.09 \mathrm{ab}$ & $1.03 \mathrm{a}$ \\
\hline & $\square$ & $0.89 \mathrm{c}$ & $0.75 \mathrm{~b}$ & $1.58 \mathrm{a}$ & $1.49 \mathrm{ab}$ & $1.08 \mathrm{~b}$ & $1.00 \mathrm{a}$ \\
\hline & $\oplus$ & $1.95 \mathrm{a}$ & $0.85 \mathrm{a}$ & $1.61 \mathrm{a}$ & $1.46 \mathrm{ab}$ & $1.17 \mathrm{ab}$ & $1.01 \mathrm{a}$ \\
\hline & $\boxplus$ & $1.20 \mathrm{~b}$ & $0.84 \mathrm{a}$ & $1.73 \mathrm{a}$ & $1.65 \mathrm{a}$ & $1.22 \mathrm{a}$ & $1.27 \mathrm{a}$ \\
\hline \multirow[t]{4}{*}{ Root } & 0 & $3.78 \mathrm{~b}$ & $3.20 \mathrm{bc}$ & $2.04 \mathrm{~b}$ & $1.81 \mathrm{~b}$ & $1.05 \mathrm{~b}$ & $1.17 \mathrm{c}$ \\
\hline & $\square$ & $3.41 \mathrm{~b}$ & $2.98 \mathrm{c}$ & $1.99 \mathrm{~b}$ & $1.79 \mathrm{~b}$ & $1.14 \mathrm{~b}$ & $1.16 \mathrm{c}$ \\
\hline & $\bar{\oplus}$ & $5.75 \mathrm{a}$ & $4.43 \mathrm{a}$ & $2.83 \mathrm{a}$ & $2.20 \mathrm{a}$ & $1.42 \mathrm{a}$ & $1.33 \mathrm{~b}$ \\
\hline & $\boxplus$ & $5.21 \mathrm{a}$ & $3.98 \mathrm{~b}$ & $2.55 \mathrm{ab}$ & $2.44 \mathrm{a}$ & $1.48 \mathrm{a}$ & $1.48 \mathrm{a}$ \\
\hline \multirow[t]{4}{*}{ New shoots } & 0 & $0.51 \mathrm{c}$ & $0.41 \mathrm{~b}$ & $0.04 \mathrm{~b}$ & $0.03 \mathrm{~b}$ & $0.02 \mathrm{c}$ & $0.01 \mathrm{~b}$ \\
\hline & $\square$ & $1.09 \mathrm{~b}$ & $0.49 \mathrm{~b}$ & $0.04 \mathrm{~b}$ & $0.03 \mathrm{~b}$ & $0.05 \mathrm{~b}$ & $0.02 \mathrm{~b}$ \\
\hline & $\oplus$ & $1.22 \mathrm{~b}$ & $1.04 \mathrm{a}$ & $0.09 \mathrm{a}$ & $0.09 \mathrm{a}$ & $0.06 \mathrm{~b}$ & $0.04 \mathrm{a}$ \\
\hline & $\boxplus$ & $1.53 \mathrm{a}$ & $0.86 \mathrm{a}$ & $0.10 \mathrm{a}$ & $0.06 \mathrm{a}$ & $0.12 \mathrm{a}$ & $0.06 \mathrm{a}$ \\
\hline \multirow[t]{4}{*}{ Total } & 0 & $7.48 \mathrm{bc}$ & $5.89 \mathrm{c}$ & $4.36 \mathrm{~b}$ & $3.89 \mathrm{c}$ & $3.48 \mathrm{c}$ & $3.35 \mathrm{~b}$ \\
\hline & $\square$ & $6.59 \mathrm{c}$ & $5.17 \mathrm{~d}$ & $4.58 \mathrm{~b}$ & $4.10 \mathrm{bc}$ & $3.61 \mathrm{bc}$ & $3.39 \mathrm{~b}$ \\
\hline & $\oplus$ & $10.59 \mathrm{a}$ & $7.97 \mathrm{a}$ & $5.52 \mathrm{a}$ & $4.58 \mathrm{ab}$ & $4.03 \mathrm{ab}$ & $3.67 \mathrm{~b}$ \\
\hline & $\boxplus$ & $9.45 \mathrm{ab}$ & $6.94 \mathrm{~b}$ & $5.50 \mathrm{a}$ & $5.02 \mathrm{a}$ & $4.19 \mathrm{a}$ & $4.17 \mathrm{a}$ \\
\hline
\end{tabular}

$\bigcirc=$ circular container; $\square=$ square container; $\oplus=$ circular container with internal vertical wall; $\boxplus=$ square container with internal vertical walls. Different letters in columns indicate significant difference at $P \leq 0.05$ according to least significant difference test.

which is confirmed by the clear association of the variables analyzed with the simple linear regression models described in both substrates (Fig. 4).

\section{Conclusions}

Walls inside containers not only reinforce a container or pot from a mechanical perspective but also deter root spiralling. In addition to decreasing root deformation (Amoroso et al., 2010; Rune, 2003), which potentially affects the anchoring of roots after transplant (Nichols and Alm, 1983) and reduces sprout growth (Ortega et al., 2006), inner walls also favor the production of biomass in horticultural plants and substantially increase total root weight, which increases a plant's ability to cope with drought stress and therefore overcome potential posttransplant stress in both substrates.

\section{Literature Cited}

Álvaro, J.E., S. Moreno, F. Dianez, M. Santos, G. Carrasco, and M. Urrestarazu. 2009. Effects of peracetic acid disinfectant on the postharvest of some fresh vegetables. J. Food Eng. 95:11-15.

Amoroso, G., P. Frangi, R. Piatti, F. Ferrini, A Fini, and M. Faoro. 2010. Effect of container design on plant growth and root deformation of littleleaf linden and field elm. HortScience 45:1824-1829.

Ansorena, M.J. 1994. Sustratos: Propiedades y Caracterización. (Substrates: Properties and characterization). Mundi-Prensa, Madrid, Spain.

Aphalo, P. and R. Rikala. 2003. Field performance of silver-birch planting-stock grown at different spacing and in containers of different volume. New For. 25:93-108.
Araki, H. and M. Iijima. 2001. Deep rooting in winter wheat: Rooting nodes of deep roots in two cultivars with deep and shallow root systems. Plant Prod. Sci. 4:215-219.

Armitage, A.M. and P.M. Gross. 1996. Coppertreated plug flats influence root growth and flowering of bedding plants. HortScience 31:941-943.

Atwell, B.J. 1993. Response of roots to mechanical impedance. Environ. Exp. Bot. 33:27-40.

Bignami, C. and F. Rossini. 1996. Image analysis estimation of leaf area index and plant size of young hazelnut plants. J. Hort. Sci. 71:113-121.

Bilderback, T.E. and W.C. Fonteno. 1987. Effects of container geometry and media physical properties on air and water volumes in containers. J. Environ. Hort. 5:180-182.

Biran, I. and A. Eliassaf. 1980. The effect of container shape on the development of roots and canopy of woody plants. Scientia Hort. 12:183-193. 
Bokmiller, D., M. Moon, R. Gumpf, S. Mullins, M. Blomerley, and S. Pavelka. 2000. Nest and stack plant pot. U.S. Patent No. $6,134,832$. U.S. Patent and Trademark Office, Washington, DC: 01-11.

Brass, T.J., G.J. Keever, D.J. Eakes, and C.H. Gilliam. 1996. Styrene-lined and copper-coated containers affect production and landscape establishment of red maple. HortScience 3:353-356.

Chirino, E., A. Vilagrosa, E.I. Hernández, A. Matos, and V.R. Vallejo. 2008. Effects of a deep container on morpho-functional characteristics and root colonization in Quercus suber L. seedlings for reforestation in Mediterranean climate. For. Ecol. Mgt. 256:779-785.

Cooley, J.N. 2011. Plant container. U.S. Patent No. 7,954,277 B2. U.S. Patent and Trademark Office, Washington, DC: 01-20.

De Rijck, G. and E. Schrevens. 1998. Distribution of nutrients and water in rockwool slabs. Scientia Hort. 72:277-285.

Dixon, G.R. 2019. Horticultural science-a century of discovery and application. J. Hortic. Sci. Biotechnol. 94:550-572.

Dominguez-Lerena, S., N.H. Sierra, I.C. Manzano, L.O. Bueno, J.P. Rubira, and J.P. Mexal. 2006. Container characteristics influence Pinus pinea seedling development in the nursery and field. For. Ecol. Mgt. 221:63-71.

Ferrand, M. 1971. Plant container. U.S. Patent No. 3,557,489. U.S. Patent and Trademark Office, Washington, DC: 01-03.

Gallegos-Cedillo, J., R. Arteaga-Ramírez, M.A. Vázquez-Peña, and J. Juárez-Méndez. 2016. Estimation of missing daily precipitation and maximum and minimum temperature records in San Luis Potosí. Ing. Agr. Biosist. 8:3-16.

García, M., M. Guzmán, M. Urrestarazu, M. Salas, and I. Escobar. 1997. Evaluación de diferentes parámetros en cultivo de perlita para distintas especies hortícolas en invernadero. (Evaluation of different parameters in perlite substrate by some vegetables in crop protection). Acta Hort. 18:519-525.

Gilman, E.F., J. Grabosky, A. Stodola, and M.D. Marshall. 2003. Irrigation and container type impact red maple (Acer rubrum L.) 5 years after landscape planting. Arboric. J. 29:231-236.

Guggenheim, T.L. and R.R. Odle. 2016. Methods to grow, deliver, and plant young trees in a removable tubular container. U.S. Patent No. 9,414,547 B2. U.S. Patent and Trademark Office, Washington, DC: 01-20.

Heller, H., A. Bar-Tal, S. Assouline, K. Narkis, S. Suryano, A. de la Forge, M. Barak, H. Alon, M. Bruner, S. Cohen, and D. Tsohar. 2015. The effects of container geometry on water and heat regimes in soilless culture: Lettuce as a case study. Irrig. Sci. 33:53-65.

Insalaco, C.J. 1975. Nursery pot having improved drainage. U.S. Patent No. 3,896,587. U.S. Patent and Trademark Office, Washington, DC: 01-06.

Kaspar, T.C. and W.L. Bland. 1992. Soil temperature and root growth. Soil Sci. 154:290-299.

Keever, G.J. and G.S. Cobb. 1987. Effects of container volume and fertility rate on growth of two woody ornamentals. HortScience 22:891-895.

Kreizel, J. 2002. Planter and method of manufacturing same. U.S. Patent No. 6,360,484 B1. U.S. Patent and Trademark Office, Washington, DC: 01-09.

Landis, T.D., T. Luna, and R.K. Dumroese. 2014 Containers, p. 123-140. In: K.M. Wilkinson, T.D. Landis, D.L. Haase, B.F. Daley, and R.K. Dumroese (eds.). Tropical Nursery Manual: A guide to starting and operating a nursery for native and traditional plants. Agriculture Handbook 732. U.S. Department of Agriculture, Forest Service, Washington, DC.
Landis, T.D. 1990. Containers and growing media, p. 41-85. In: T.D. Landis, R.W. Tinus, S.E. McDonald, and J.P. Barnett (eds.). The container tree nursery manual, Vol. 2. Agricultural Handbook 674. U.S. Department of Agriculture, Forest Service, Washington, DC.

Lemaire, F. and J.L. Papin. 1989. Influence of the physical characteristics of substrate on the root systems of ornamental plants grown in pots and containers. Agronomie 9:795-801.

Lemaire, F., A. Dartigues, L.M. Riviére, S. Charpentier, and P. Morel. 2005. Cultivos en macetas y contenedores. Principios agronómicos $\mathrm{y}$ aplicaciones [Cultivation in pots and containers. Agronomic principles and applications]. 2nd ed. Mundi-Prensa, Madrid, Spain.

Liptay, A. and D. Edwards. 1994. Tomato seedling growth in response to variation in root container shape. HortScience 29:633-635.

Lüken, R. and A. Sieverding. 2009. Flower pot. U.S. Patent No. 7,610,717 B2. U.S. Patent and Trademark Office, Washington, DC: 01-09.

Mansoorkhani, F., G.B. Seymour, R. Swarup, H.M. Moeiniyan-Bagheri, R.J.L. Ramsey, and A.J. Thompson. 2014. Environmental, developmental, and genetic factors controlling root system architecture. Biotechnol. Genet. Eng. 30:95112.

Mascarini, L., G. Lorenzo, H. Svartz, S. Pesenti, and S. Amado. 2012. Container size and growing media affects water use efficiency in a Gerbera jamesonii cut flower crop. Rev. Bras. Hort. Ornam. 18:71-77.

Montgomery, D.C. 2004. Design and analysis of experiments. 2nd ed. John Wiley \& Sons, Phoenix, AZ.

Neddo, K.S., G.M. Alder, and J.L. Gwilliam. 1977. Seedling plant propagation container. U.S. Patent No. 4,006,558. U.S. Patent and Trademark Office, Washington, DC: 01-05.

Nichols, T.J. and A.A. Alm. 1983. Root development of container-reared, nursery-grown, and naturally regenerated pine seedlings. Can. J. For. Res. 13:239-245.

Nilsson, T. and U. Fransson. 2017. Pluggtrainer. U.S. Patent No. 9,795,090 B2. U.S. Patent and Trademark Office, Washington, DC: 01-15.

Ortega, U., J. Majada, A. Mena-Petite, J. SanchezZabala, N. Rodriguez-Iturrizar, K. Txarterina, J. Azpitarte, and M. Duñabeitia. 2006. Field performance of Pinus radiata $\mathrm{D}$. Don produced in nursery with different types of containers. New For. 31:97-112.

Park, G.B. 1966. Plant shipping container. U.S. Patent No. 3,284,949. U.S. Patent and Trademark Office, Washington, DC: 01-03.

Pemán, J., J. Voltas, and E. Gil-Pelegrin. 2006. Morphological and functional variability in the root system of Quercus ilex L. subject to confinement: Consequences for afforestation. Ann. For. Sci. 63:425-430.

Quan, T.Z., J.H. Wu, and X. Wang. 2011. Nursery container. U.S. Patent No. 0,232,187 A1. U.S Patent and Trademark Office, Washington, DC: 01-13.

Reid, J., D. Winfield, I. Sorensen, and A. Kale. 1996. Water deficit, root demography, and the causes of internal blackening in field-grown tomatoes: (Lycopersicon esculentum Mill.). Ann. Appl. Biol. 129:137-149.

Rodríguez, D., J. Reca, J. Martínez, M.T. Lao, and M. Urrestarazu. 2014. Effect of controlling the leaching fraction on the fertigation and production of a tomato crop under soilless culture. Scientia Hort. 179:153-157.

Rodríguez, D., J. Reca, J. Martínez, R. LópezLuque, and M. Urrestarazu. 2015. Development of a new control algorithm for automatic irrigation scheduling in soilless culture. Appl. Math. Inf. Sci. 9:47-56.

Rune, G. 2003. Slits in container wall improve root structure and stem straightness of outplanted Scots pine seedlings. Silva Fenn. 37:333-342.

Sánchez-Aguilar, H., A. Aldrete, J. VargasHernández, and V. Ordaz-Chaparro. 2016. Influence of container type and color on seedling growth of pine in nursery. Agrociencia 50:481492.

Schmidt, G. 2009. Plastic plant pot. U.S. Patent No. 7,624,535 B2. U.S. Patent and Trademark Office, Washington, DC: 01-08.

Schromm, F. 2009. Container with plant identification tag slot. U.S. Patent No. 7,624,536 B2. U.S. Patent and Trademark Office, Washington, DC: 01-10.

Salter, P.J. 1961. The irrigation of early summer cauliflower in relation to stage of growth, plant spacing and nitrogen level. J. Hort. Sci. Biotechnol. 36:241-263.

Sieverding, L.A. 2007. Plant pot made from deepdrawn plastic. U.S. Patent No. 7,204,056 B2. U.S. Patent and Trademark Office, Washington, DC: 01-09.

Skinner, R.B. 2002. Container and tag assembly. U.S. Patent No. 6,463,696 B2. U.S. Patent and Trademark Office: 01-15, Washington, DC.

Sonneveld, C. and N. Straver. 1994. Nutrient solutions for vegetables and flower grown in water or substrates, p. 1-45. 10th Proefstation voor Tuinbouw Onder Glas te Naaldwijk, Naaldwijk.

South, D.B., S.W. Harris, J.P. Barnett, M.J. Hainds, and D.H. Gjerstad. 2005. Effect of container type and seedling size on survival and early height growth of Pinus palustris seedlings in Alabama, USA. For. Ecol. Mgt. 204:385-398.

Spencer, H.A. 1972. Planting from the book. For. Chron. 48:240-241.

Spencer, H.A. 1977. Container for seedlings. U.S. Patent No. 4,057,932. U.S. Patent and Trademark Office, Washington, DC: 01-16.

Spencer, H.A. 1991. Book-type container for raising seedlings. U.S. Patent No. 4,998,378. U.S. Patent and Trademark Office, Washington, DC: 01-05.

Staby, G.L. 1979. Container with raised indentations for aeration and drainage. U.S. Patent No. 4,173,097. U.S. Patent and Trademark Office, Washington, DC: 01-06.

Stockdale, W.D. 1961. Plastic flower pot. U.S. Patent No. 3,009,603. U.S. Patent and Trademark Office, Washington, DC: 01-03.

Trinidad, O.S., H.J. Vargas, A. Aldrete, U.J. López, and G.A.M. Fierros. 2015. Substrate and container size over the development of Hevea brasiliensis Müll. Arg. at the nursery. Rev. Mex. Cienc. For. 6:94-113

Urrestarazu, M. 2015. Manual Práctico del Cultivo Sin Suelo e Hidroponía, p. 1-267 [Handbook of soilless culture and hydroponics]. MundiPrensa, Madrid, Spain.

Urrestarazu, M., V. Gallegos, and J.E. Álvaro. 2017. The use of thermography images in the description of the humidification bulb in soilless culture. Commun. Soil Sci. Plant 48:15951602 .

Urrestarazu, M., V.M. Gallegos-Cedillo, F. FerrónCarrillo, J.L. Guil-Guerrero, M.T. Lao, and J.E. Álvaro. 2019. Effects of the electrical conductivity of a soilless culture system on gamma linolenic acid levels in borage seed oil. PLoS One 14:e207106.

Urrestarazu, M., I. Morales, T. La Malfa, R. Checa, A.F. Wamser, and J.E. Álvaro. 2015. Effects of fertigation duration on the pollution, water 
consumption, and productivity of soilless vegetable cultures. HortScience 50:819-825.

Urrestarazu, M., M. Salas, D. Valera, A. Gómez, and P.C. Mazuela. 2008. Effects of heating nutrient solution on water and mineral uptake and early yield of two cucurbits under soilless culture. J. Plant Nutr. 31:527-538.
Van Noordwijk, M. and P.A.C. Raats. 1980. Drip and drainage systems for rockwool cultures in relation to accumulation and leaching of salts. Proc. 5th Intl. Congr. Soilless Cult. p. 279-287. Verlodt, H. and S. Kamoun. 1981. Influence of the volume of the growth bags and the addition of well-made manure to a compost of the seagrass Posidonia oceanica L. Del. on the behavior of tomato crop under plastic greenhouse. Acta Hort. 126:263-272.

Yano, T., A. Morisaki, S. Ito, and M. Kitano. 2018. A generalized linear model to predict the growth of potted seedlings of Satsuma mandarin (Citrus unshiu Marcow.) under different initial plant conditions, environmental conditions, and pot size. Hort. J. 87:490-498. 